- Editorial Notes •

\title{
Preface to the Special Issue on Extreme Cold Events from East Asia to North America in Winter 2020/21 $\%$
}

\author{
Mu MU1', Dehai LUO², and Fei ZHENG ${ }^{3}$ \\ ${ }^{1}$ Department of Atmospheric and Oceanic Sciences and Institute of Atmospheric Sciences, \\ Fudan University, Shanghai 200438, China \\ ${ }^{2}$ CAS Key Laboratory of Regional Climate-Environment for Temperate East Asia, Institute of Atmospheric Physics, \\ Chinese Academy of Sciences, Beijing 100029, China \\ ${ }^{3}$ International Center for Climate and Environment Science (ICCES), Institute of Atmospheric Physics, \\ Chinese Academy of Sciences, Beijing 100029, China
}

\begin{abstract}
Citation: Mu, M., D. H. Luo, and F. Zheng, 2022: Preface to the Special Issue on Extreme Cold Events from East Asia to North America in Winter 2020/21. Adv. Atmos. Sci., 39(4), 543-545, https://doi.org/10.1007/s00376-021-1004-3.
\end{abstract}

\begin{abstract}
Along with anthropogenic global warming, the Northern Hemisphere $(\mathrm{NH})$ has experienced more frequent cold air outbreaks and heavy snowfalls in recent decades (Petoukhov and Semenov, 2010; Liu et al., 2012; Cohen et al., 2014; 2020; Overland et al., 2015). The most recent example of extreme winter weather was the extreme cold events that occurred from East Asia to North America during the winter of 2020/21 (Cohen et al., 2021; Zheng et al., 2022a). An early observational study argued that Arctic amplification contributes to more extreme weather in all seasons (e.g., Francis and Vavrus, 2012), manifested by a warmer surface and lower troposphere and a consequent decline in sea ice. Newson (1973) first noted that Arctic amplification could reduce the zonal momentum of midlatitude westerly winds and favor blocking flows, a theoretically justifiable response to a reduced meridional temperature gradient. More recent studies have suggested that frequent Eurasian cold extremes were associated with the loss of Arctic sea ice (Liu et al., 2012; Tang et al., 2013; Mori et al., 2014; Kug et al., 2015) through the promotion of more blocking events and the subsequent invasions of Arctic air into Eurasia. However, McCusker et al. (2016) and Sun et al. (2016) argued that declines in Arctic sea ice do not play a role in the midlatitude cold extremes, citing the cold-air outbreaks of the 1960s when Arctic sea ice was abundant.

Whether a decline of Arctic sea ice significantly influences mid-latitude weather patterns also depends on the timescale considered. On the long-term trend or interdecadal timescales, the impact of Arctic sea-ice decline or Arctic amplification on the mid-latitude atmospheric circulation and associated cold extremes is less important (Dai and Song, 2020), despite the existence of a warm Arctic-cold Eurasia pattern on decadal timescales (Shepherd, 2016). However, on shorter time scales (interannual and seasonal), a decline in Arctic sea ice can influence mid-latitude atmospheric circulations and associated cold anomalies (Luo et al., 2016). Thus, large uncertainty still exists about whether Arctic amplification influences mid-latitude cold extremes, even though many studies have discussed the Arctic-midlatitude linkage.

It is recognized that the cold winter extremes over Eurasia, especially over Siberia, are mainly associated with Ural blocking. Although Ural blocking results from the propagation of wave trains associated with the decay of a positive North Atlantic Oscillation, the Arctic sea ice decline over the Barents-Kara Seas can increase the quasi-stationarity and persistence of Ural blocking (Yao et al., 2017) that favor the Eurasian cold extremes by reducing the meridional background potential vorticity gradient (Luo et al., 2019). Synergistic effects between the Arctic and tropical oceans have also been proposed and investigated as to their ability to modulate the changes in the middle- and high-latitude atmospheric circulation (e.g., Basu et al., 2013; Barnes and Polvani, 2015), although it is still difficult to acquire consistently observed or simulated evidence of the Arctic-tropical ocean temperature difference affecting extreme cold events in the background context of Arctic warming, mainly due to limited event samples.

In considering the record-breaking cold surface air temperatures with strong winds that occurred over East Asia and North America during the 2020/21 winter, identification and comprehension of the possible underlying physical processes, from weather to climate time scales, that triggered and enhanced these extreme cold events become uniquely necessary for
\end{abstract}

※ This paper is a contribution to the special issue on Extreme Cold Events from East Asia to North America in Winter 2020/21. 
exploration and research. This special issue showcases recent research progress and applies the existing knowledge regarding the NH extreme cold events that occurred in the winter of 2020/21. It has solicited a total of nine articles, covering a broad scope of research topics.

Zheng et al. (2022a) first pointed out that the middle- and high-latitude, large-scale atmospheric circulation anomalies associated with the negative phase of the North Atlantic Oscillation (NAO), a strengthened Siberian High, an intensified Ural High, and a deepened East Asian Trough, were the direct reasons for the frequent cold surges in winter 2020/21. The analysis by Zhang et al. (2022a) further indicated that the occurrences of the three striking and impactful extreme cold weather events across East Asia and North America during the mid-winter of 2020/21 resulted from the integrated effects of a concurrence of anomalous thermal conditions in three ocean basins and an interactive Arctic-lower latitude atmospheric circulation process, which were linked through and influenced by one major sudden stratospheric warming (SSW) event. Zhang et al. (2022b) also demonstrated the major SSW event occurred at the beginning of January 2021 exerted an important influence on the extreme cold wave in East Asia through inducing the stratospheric warming signal to propagate downward to the middle to lower troposphere, which not only enhanced the Urals-Siberia blocking and the negative phase of Atlantic Oscillation (AO), but also shifted the tropospheric polar vortex off the pole.

Research on the extreme cold events in winter 2020/21 has been approached from different perspectives. Bueh et al. (2022) compared the distinct features of these extreme cold events at a medium-range time scale and suggested that an extensive and zonally-oriented accumulation of Siberian cold air was the primary reason for their occurrence. Yao et al. (2022) explained that successive Ural blocking (UB) episodes that occurred from fall 2020 to January 2021 served as a crucial physical mechanism that allowed for an efficient cold-air transport process into East Asia, and went on to suggest further that the cumulative seasonal effects of UBs, combined with the impact of La Niña, can lead to the frequent occurrence of extreme cold events. Li et al. (2022) investigated the influence of the winter NAO on the multidecadal variability of winter East Asian surface air temperature (EASAT). They proposed that the coupled oceanic-atmospheric bridging mechanism of the NAO influences the winter EASAT multidecadal variability. Yu et al. (2022) also investigated possible mechanisms from an isentropic mass circulation (IMC) perspective. They stated that these cold events were always associated with strengthening the low-level equatorward cold air branch of the IMC.

For the predictability of the extreme cold event itself and its related contributing factors (i.e., the 2020/21 La Niña, and 2020 Arctic sea ice loss) in 2020/21, Dai et al. (2022) evaluated the forecast skill for the three cold events in 2020/21 by utilizing the operational forecasts from the ECMWF model and found that the third event had the highest predictability. They also suggested a relationship between the cold events and the initial atmospheric conditions and that the effects of Arctic sea ice and La Niña need to be further investigated. Furthermore, through adopting state-of-art coupled models, Zheng et al. (2022b) evaluated the potential predictive skill of ocean environments, as their covariations may have contributed to the 2020/21 extreme cold events in China. They demonstrated further that the predominant southeasterly wind anomalies over the equatorial Pacific in spring 2020 played an irreplaceable role in triggering the 2020/21 La Niña event; and that an anomalous cyclonic circulation advected abnormally warm air initially over Siberia into the Arctic Ocean, which contributed to the sea ice loss in autumn 2020. At the decadal time scale, Li et al. (2022) indicated that it is common for East Asia to frequently experience extreme cold events over the next few years and that the predicted winter EASATs for 2020-24 will keep on fluctuating downward until 2025 . Overall, the 2020/21 NH extreme cold events provided an opportunity to explore the possible physical processes and evaluate the real-time predictive skills of the state-of-art models. However, the predictability and physical mechanisms related to the onset and evolution of the extreme cold events from East Asia to North America are still open topics for future research, especially in the context of a significant global warming background.

\section{REFERENCES}

Barnes, E. A., and L. M. Polvani, 2015: CMIP5 projections of Arctic amplification, of the North American/North Atlantic circulation, and of their relationship. J. Climate, 28, 5254-5271, https://doi.org/10.1175/JCLI-D-14-00589.1.

Basu, S., X. D. Zhang, I. Polyakov, and U. S. Bhatt, 2013: North American winter-spring storms: Modeling investigation on tropical Pacific sea surface temperature impacts. Geophys. Res. Lett., 40, 5228-5233, https://doi.org/10.1002/grl.50990.

Bueh, C., J. B. Peng, D. W. Lin, and B. M. Chen, 2022: On the two successive supercold waves straddling the end of 2020 and the beginning of 2021. Adv. Atmos. Sci., https://doi.org/10.1007/s00376-021-1107-x.

Cohen, J., and Coauthors, 2014: Recent Arctic amplification and extreme mid-latitude weather. Nature Geoscience, 7, 627-637, https:// doi.org/10.1038/ngeo2234.

Cohen, J., and Coauthors, 2020: Divergent consensuses on Arctic amplification influence on midlatitude severe winter weather. Nature Climate Change, 10, 20-29, https://doi.org/10.1038/s41558-019-0662-y.

Cohen, J., L. Agel, M. Barlow, C. I. Garfinkel, and I. White, 2021: Linking Arctic variability and change with extreme winter weather in the United States. Science, 373(6559), 1116-1121, https://doi.org/10.1126/science.abi9167.

Dai, A. G., and M. R. Song, 2020: Little influence of Arctic amplification on mid-latitude climate. Nature Climate Change, 10, 231-237, https://doi.org/10.1038/s41558-020-0694-3. 
Dai, G. K., C. X. Li, Z. Han, D. H. Luo, and Y. Yao, 2022: The nature and predictability of the east Asian extreme cold events of 2020/21. Adv. Atmos. Sci., https://doi.org/10.1007/s00376-021-1057-3.

Francis, J. A., and S. J. Vavrus, 2012: Evidence linking Arctic amplification to extreme weather in mid-latitudes. Geophys. Res. Lett., 39(6), L06801, https://doi.org/10.1029/2012GL051000.

Kug, J. S., J. H. Jeong, Y. S. Jang, B. M. Kim, C. K. Folland, S. K. Min, and S. W. Son, 2015: Two distinct influences of Arctic warming on cold winters over North America and East Asia. Nature Geoscience, 8(10), 759-762, https://doi.org/10.1038/ngeo2517.

Li, J. P., T. J. Xie, X. X. Tang, H. Wang, C. Sun, J. Feng, F. Zheng, and R. Q. Ding, 2022: Influence of the NAO on wintertime surface air temperature over East Asia: Multidecadal variability and decadal prediction. Adv. Atmos. Sci., https://doi.org/10.1007/s00376021-1075-1.

Liu, J. P., J. A. Curry, H. J. Wang, M. R. Song, and R. M. Horton, 2012: Impact of declining Arctic sea ice on winter snowfall. Proceedings of the National Academy of Sciences of the United States of America, 109, 4074-4079, https://doi.org/10.1073/pnas. 1114910109

Luo, D. H., Y. Xiao, Y. Yao, A. Dai, I. Simmonds, and C. Franzke, 2016: The impact of Ural blocking on winter warm Arctic-cold Eurasian anomalies. Part I: Blocking-induced amplification. J. Climate, 29, 3925-3947.

Luo, D. H., X. D. Chen, J. Overland, I. Simmonds, Y. T. Wu, and P. F. Zhang, 2019: Weakened potential vorticity barrier linked to recent winter Arctic sea ice loss and midlatitude cold extremes. J. Climate, 32, 4235-4261, https://doi.org/10.1175/JCLI-D-180449.1.

McCusker, K. E., J. C. Fyfe, and M. Sigmond, 2016: Twenty-five winters of unexpected Eurasian cooling unlikely due to Arctic sea-ice loss. Nature Geoscience, 9, 838-842, https://doi.org/10.1038/ngeo2820.

Mori, M., M. Watanabe, H. Shiogama, J. Inoue, and M. Kimoto, 2014: Robust Arctic sea-ice influence on the frequent Eurasian cold winters in past decades. Nature Geoscience, 7, 869-873, https://doi.org/10.1038/ngeo2277.

Newson, R. L., 1973: Response of a general circulation model of the atmosphere to removal of the arctic ice-cap. Nature, 241, 39-40, https://doi.org/10.1038/241039b0.

Overland, J., J. A. Francis, R. Hall, E. Hanna, S.-J. Kim, and T. Vihma, 2015: The melting Arctic and midlatitude weather patterns: Are they connected. . J. Climate, 28, 7917-7932, https://doi.org/10.1175/JCLI-D-14-00822.1.

Petoukhov, V., and V. A. Semenov, 2010: A link between reduced Barents-Kara sea ice and cold winter extremes over northern continents. J. Geophys. Res., 115, D21111, https://doi.org/10.1029/2009JD013568.

Shepherd, T. G., 2016: Effects of a warming Arctic. Science, 353, 989-990, https://doi.org/10.1126/science.aag2349.

Sun, L. T., J. Perlwitz, and M. Hoerling, 2016: What caused the recent "warm Arctic, cold continents" trend pattern in winter temperatures. . Geophys. Res. Lett., 43, 5345-5352, https://doi.org/10.1002/2016GL069024.

Tang, Q. H., X. J. Zhang, X. H. Yang, and J. A. Francis, 2013: Cold winter extremes in northern continents linked to Arctic sea ice loss. Environmental Research Letters, 8(1), 014036, https://doi.org/10.1088/1748-9326/8/1/014036.

Yao, Y., D. H. Luo, A. G. Dai, and I. Simmonds, 2017: Increased quasi stationarity and persistence of winter Ural blocking and Eurasian extreme cold events in response to arctic warming. Part I: Insights from observational analyses. J. Climate, 30, 3549-3568, https://doi.org/10.1175/JCLI-D-16-0261.1.

Yao, Y., W. Q. Zhang, D. H. Luo, L. H. Zhong, and L. Pei, 2022: Seasonal cumulative effect of Ural blocking episodes on the frequent cold events in China during the early winter of 2020/21. Adv. Atmos. Sci., https://doi.org/10.1007/s00376-021-1100-4.

Yu, Y. Y., Y. F. Li, R. C. Ren, M. Cai, Z. Y. Guan, and W. Huang, 2022: An isentropic mass circulation view on the extreme cold events in 2020/2021 winter. Adv. Atmos. Sci., in press, https://doi.org/10.1007/s00376-021-1289-2.

Zhang, X. D., Y. F. Fu, Z. Han, J. E. Overland, A. Rinke, H. Tang, T. Vihma, and M. Y. Wang, 2022a: Extreme cold events from East Asia to North America in winter 2020/21: Comparisons, causes, and future implications. Adv. Atmos. Sci., https://doi.org/10.1007/ s00376-021-1229-1.

Zhang, Y. X., D. Si, Y. H. Ding, D. B. Jiang, Q. Q. Li, and G. F. Wang, 2022b: Influence of major stratospheric sudden warming on the unprecedented cold wave in East Asia in January 2021. Adv. Atmos. Sci., https://doi.org/10.1007/s00376-022-1318-9.

Zheng, F., and Coauthors, 2022a: The 2020/21 extremely cold winter in China influenced by the synergistic effect of La Niña and warm Arctic. Adv. Atmos. Sci., https://doi.org/10.1007/s00376-021-1033-y.

Zheng, F., and Coauthors, 2022b: The predictability of ocean environments that contributed to the 2020/21 extreme cold events in China: 2020/21 La Niña and 2020 Arctic sea ice loss. Adv. Atmos. Sci., https://doi.org/10.1007/s00376-021-1130-y. 